Kaplan. Mf F. Stimulus inconsistency and response dispositions in forming judgments of other persons. Journal of Personality \& Social Psychology, 1973, 25, 58-64.

Levin. I. P. Learning effects in information integration: Manipulation of cue validity in an impression formation task. Memory \& Cognition, 1973, 1, 236-240.

Rosenbaum, M. E., \& Levin. I. P. Impression formation as a function of source credibility and order of presentation of contradictory information. Journal of Personality \& Social Psychology, 1968, 10,167-174.

(Received for publication September 28, 1973.)

\title{
The enhancement of schedule-induced polydipsia by preschedule noncontingent shock*
}

\section{GLEN D. KING \\ Auburn Lniversity. Auburm. Alabama 36830}

Eight food-deprived female albino rats, with electrode attachments to the back of their necks, were divided into two groups, a shock-before-schedule group and a no-shock-before-schedule group, with four Ss in each group. Ss were subjected to five successive experimental phases, during each of which individual water intakes were recorded for each 200-min daily session. The predicted result, that electric shock preceding the reinforcement schedule condition would lead to increases in water intakes, was generally upheld by the data. Increases in drinking associated with shock appeared to be a result of both increased frequency of drink bout initiation and a lengthening of the lick burst.

In early descriptions of schedule-induced polydipsia (Falk, 1961. 1964), naive rats which were receiving 45-mg food pellets on a VI 1-min schedule drank an average of $92.5 \mathrm{ml}$ of water in a $3-\mathrm{h}$ session, whereas the average 24 -h water intake of a rat in the home cage was about $20-25 \mathrm{ml}$.

Segal \& Oden (1965) proposed that excessive drinking in schedule-induced polydipsia (SIP) develops as a result of any one or a combination of determinants, including timing behaviors, adventitious reinforcement, a thirst state, and "emotional pacification," which may be akin to the anxiety assumed to underlie compulsive eating or drinking in humans. A great deal of research has been devoted to assessing the credibility of the first three of these possible explanations for SIP, but relatively little experimental investigation has been devoted to

*This article is based upon data contained in a doctoral dissertation submitted to Florida State University in partial fulfillment of requirements for the PhD degree. Robert $W$ Schaeffer sponsors the paper and takes full editorial responsibility for its contents. This research was supported in part by Public Health Service Research Granst $\mathrm{MH}-08755$ and MH-12025, Robert W. Schaeffer, principal investigator, and by the Auburn University Research Council. determining the role of emotional factors in the initiation and maintenance of SIP.

Although it may be difficult at first to accept the notion that excessive water intake may develop in organisms as a result of emotional arousal, various experiments have provided strong evidence that this may be the case. It appears that excessive drinking occurs, or is substantially enhanced, by raising monkeys in total isolation (Miller, Mirsky, Caul, \& Sakata, 1969), exposing rats to a strange environment with or without shock (Moyer, 1965), and applying mild noncontingent footshock to polydipsic rats (Segal \& Oden, 1969).

An explanation of these experimental findings may be that when an organism is exposed to conditions such as food deprivation, intermittent schedules of reinforcement, and other potentially aversive stimuli, an emotional state develops in the organism which produces an energization of the most highly probable response. In SIP, excessive drinking occurs because when the rat consumes food it is highly probable that drinking will follow, and this is the response which is energized. If SIP is an energization of the normal drinking response following food reinforcement due to some emotional state, the amount of drinking, as the indicator of the intensity of that emotional state, should be subject to change by altering the emotional state.

The purpose of this experiment was to determine if an intensified emotional state, induced by an intermittent presentation of food, can be further increased by the additional stress of electric shock, as would be indicated by an increase in the amount of drinking during a shock-plus-intermittent-schedule phase, relative to the usual polydipsia situation without shock.

\section{METHOD}

Subjects

The Ss were eight naive female albino Dublin SDD/DR rats, approximately $120-150$ days old. The animals were individually housed under conditions of constant illumination, temperature, and humidity. During the experiment, the Ss were maintained at $80 \%$ of their free-feeding weights, with water freely available in 


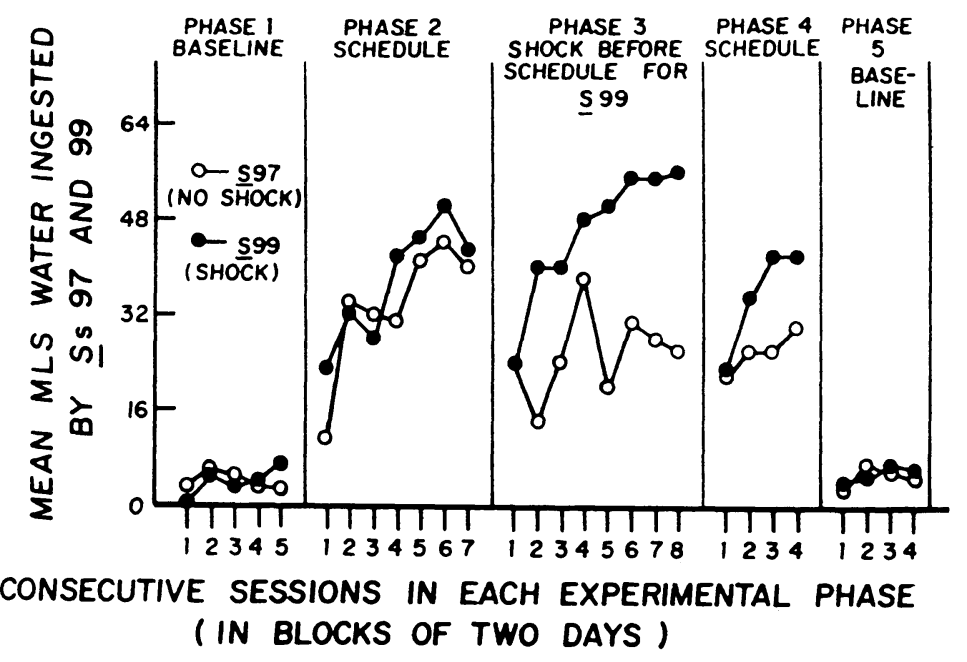

Fig. 1. Water intakes during each experimental phase (baseline, schedule, and shock before schedule or no shock before schedule) for S 97 and S 99.

the home cage and in the experimental chamber.

\section{Apparatus}

Eight Lehigh Valley Electronics Model 1316 experimental chambers were employed. In all of these chambers, the right lever was removed to allow for the insertion of the spout of a drinking tube. The end of the spout was slightly recessed from the face of the stimulus wall inside the chamber. Firmly attached to the top of each Plexiglas experimental chamber, was a clarostat potentiometer, Model 7936-10. Attached to the base of each potentiometer, which extended into the chamber, was a spring. approximately $14 \mathrm{~cm}$ in length, with an adjustable pin at the free end. This pin was attached to an electrode pin present in the back of the neck of each experimental S. Each potentiometer was modified slightly to allow the animal free access to all parts of the experimental chamber, while still retaining electrical continuity for delivery of shock. The unscrambled electrical shock was delivered by a Grason-Stadler shock generator. Model E6070B. Delivery of 2-mA, .5-sec electric shock. reinforcement (45-mg Noyes food pellets) on a FFI 60 -sec schedule. and recording of shocks and appropriate responses were programmed by standard relay circuitry.

\section{Procedure}

Prior to the beginning of this experiment, all animals were anesthetized with ether briefly to insert the safety pin electrode in the back of their necks. Occasionally, these pins would grow out, requiring periodic anesthetization of the animal and replacement of the electrode pin. These electrode replacements were made immediately following the daily sessions in which the pin was lost, to minimize the possibility that the minor surgical operation would affect experimental results.

Initially, Ss spent the first $100 \mathrm{~min}$ of each 200 -min daily session with no food or shock. Water, on the other hand, was freely available in the chambers at all times during the experiment. In the second $100 \mathrm{~min}$ of each daily session, 100 $45-\mathrm{mg}$ Noyes food pellets were placed in the food magazine to accomplish magazine training. This baseline condition continued until water intake stabilized for all Ss. Stabilization for all phases in this experiment was defined as the condition in which the mean water intake for the last three sessions, minus the mean for the preceding three sessions, divided by the mean of the last six sessions did not exceed $20 \%$.

After stabilization of water intake in baseline, the polydipsia development and stabilization phase began. As before, all Ss spent the first $100 \mathrm{~min}$ in the experimental chambers with only water freely available. However, in the second $100 \mathrm{~min}$ of the experimental session, an intermittent food reinforcement schedule was programmed in which $10045-\mathrm{mg}$ Noyes food

pellets were delivered on a FFI 60-sec schedule. A FFI schedule delivers reinforcement on a FI periodic schedule, independently of the organism's behavior. This second, or developmental phase, continued un iil polydipsia reached stability.

Before the third phase of the experimental commenced, the eight Ss were paired and assigned to an experimental group or a control group, with four Ss in each group. The Ss were matched in such a manner that the amount of water ingested during daily sessions in Phase 2 was approximately equal for both animals in each pair. Following this matching procedure, one $S$ from each pair was assigned to a control group and the other $S$ to the experimental group. The third phase of the experimental procedure was the same as the second phase, with the exception that the first $100 \mathrm{~min}$ of the experimental session was then devoted to inducing an intense state in the experimental group Ss. The Ss in the experimental group received 100 shocks on a FFI 60 -sec schedule. The control Ss had the same electrode attachments as the experimental Ss, but they received no electrical shock. After $100 \mathrm{~min}$ of the shock condition, shock was discontinued and $10045-\mathrm{mg}$ food pellets were delivered to all Ss on the FFI 60-sec schedule, as in Phase 2. Phase 3 continued until the water intake for the experimental (shock) group stabilized.

Phase 4 was a repetition of Phase 2, and when water intakes became stable in Phase 4, Phase 5 (baseline), which was a repetition of Phase 1, began.

\section{RESULTS AND DISCUSSION}

The water intakes for each individual in a generally representative matched pair during each of the five experimental phases is presented in Fig. 1. The matching control procedure was instituted to detect any decrements in water intake in animals that received no shock that may have occurred parmarily as an adaptation to the stress of the schedule conditions. However, it was clear from the data that no general trends of decrements in water intakes in nonshocked animals were observed. Although there was a great deal of variability within individual animals, the general trend of the results, as presented in Fig. 1. indicated that both shocked and nonshocked animals increased water intakes during intermittent schedule conditions (Phases 2 and 4) relative to the pre-and postschedule baseline conditions. Further, and most important, when stability was reached during Phase 3, the water intake for three of the four Ss 
in the shock group was greater than the water intake for their respective matched controls in the noshock group.

An analysis of variance, repeated measures with a nested design (trials within conditions), was conducted for within- and between-group water intakes using the BMD08V computer program. These analyses were conducted to compare the water intakes across conditions and trials in the no-shock group, shock group, and between both groups. The analyses indicated that water intakes increased significantly during the schedule condition, relative to the baseline conditions, for both shock and no-shock groups $(p<.05)$. When only the schedule and shock-before-schedule conditions were compared, both groups showed no difference in water intakes and there was no apparent difference in water intakes between the schedule and shock-before-schedule conditions $(\mathrm{p}>.05)$.

However, inspection of the data from one matched pair indicated that one shocked $S$ did not develop polydipsia, as its water intakes during the schedule conditions were not significantly different from water intakes during the baseline conditions. When this S's data were dropped and the analysis was conducted again, it became immediately apparent that considering only those animals that were polydipsic when the third phase was begun, the water intakes showed an increase in the shock-before-schedule condition relative to the schedule-alone conditions, whereas the Ss in the no-shock group did not show a significant difference between schedule conditions and the no-shock-control-schedule condition. In observing the $\mathrm{S}$ that did not develop SIP, it was evident that immediately following pellet delivery, it ate and then attacked the electrode implant. Furthermore, this attack became more intense when shock preceded the schedule condition. We predicted that the most highly probable response following reinforcement should be energized, and in the case of this $S$, the most highly probable response seemed to be attack or aggression toward the electrode. In this regard, as the attack response became more intense with the added stress of shock, we would predict that even less drinking should occur during the shock-before-schedule condition than in the schedule-alone or baseline conditions, since the competing attack response would result in a decrease in drinking in Phase 3 (shock before schedule) relative to Phases 1, 2, and 5. The continued low water intakes in Phase 4, which appeared to increase at the end of the schedule condition, may have been due to a conditioned emotional reaction to the surrounding stimuli.

In a study by Siegel \& Siegel (1949), drinking was also increased in rats by shocking the animals just prior to normal daily drinking sessions. However, those investigators noted that increases in drinking occurred during the initial period of availability of water immediately following termination of the shock condition. An analysis of Esterline-Angus records, determining the number of pellets followed by drinking for all Ss for the entire 100 pellets and for the first 20 pellets, indicated that drinking was generally more probable following food pellet delivery in the shock-before-schedule condition compared to the schedule conditions alone. However, this also appeared to be true for the no-shock controls. In considering drinking after only the first 20 pellets, there was evidence that relative to both schedule conditions, the shocked Ss drank more often after the initial pellet deliveries in Phase 3 than did the nonshocked controls, but it is doubtful that an increased probability in drinking after food-pellet delivery is alone responsible for the increased water intakes of the shock group in Phase 3.

In this regard, lick burst lengths were determined for each animal during the last 2 days of each condition. The data suggest that the increases in drinking are primarily due to increases in frequency with which lick bursts are initiated. However, there seems to be a slight trend in the data which indicates that, for the shocked animals (excluding S 102), there is a lengthening of lick bursts during the preschedule shock condition relative to the no-shock schedule conditions, as indicated by larger percentages of drinking bouts occurring in the longer lick ranges relative to both previous and following schedule conditions.

The results of this study may be interpreted as adding support to the theoretical notion that the addition of a stressor (shock) to already present stressors (deprivation and intermittent schedule conditions) will result in an increase in the intensity of the resultant emotional response, in this case, drinking water. Furthermore, the one animal that did not become polydipsic was observed to increase the intensity of the response that seemed to be most highly probable following reinforcement delivery, other than drinking water (attack of the electrode), when the extra stress of shock was applied. The increased drinking during the shock condition was attributable to both an increased frequency of initiation of drinking and to a slight lengthening of lick burst length.

\section{REFERENCES}

Falk, J. L. Production of polydipsia in normal rats by an intermittent food schedule. Science, 1961, 133, 195-196.

Falk, J. L. Studies on schedule-induced polydipsia. In M. J. Wayner (Ed.), Thirst: First international symposium on thirst in the regulation of body water. New York: Pergammon Press, 1964. Pp. 95-116.

Miller, R. E., Mirsky, I. A., Caul, W. F., \& Sakata, T. Hyperphagia and polydipsia in socially isolated rhesus monkeys. Science, 1969, 165, 1027-1028.

Moyer, K. E. Effect of experience with emotion provoking stimuli on water consumption in the rat. Psychonomic Science, 1965, 2, 251-252.

Segal, E. F., \& Oden, D. L. Determinants of polydipsia in rats: A reply to Stein. I. Emptying the water bottle. Psychonomic Science, 1965, 2, 201-202.

Segal, E. F., \& Oden, D. L. Effects of drinkometer current and of foot shock on psychogenic polydipsia. Psychonomic Science, 1969, 14, 13-15.

Siegel, P. S., \& Siegel, H. S. The effect of electroconvulsive shock on the anticipatory gradient in the rat. Journal of Comparative \& Physiological Psychology, 1949, 62, 405-411.

(Received for publication October 9, 1973.) 